\title{
Electrocatalytic performance of Au@Cu Nanoparticle Chains as Sensor for Determination of Piroxicam
}

\author{
$\mathrm{Na} \mathrm{Wu}^{1,2}$, Guanmei Yang ${ }^{1,2}$, Jinming Meng ${ }^{1,2}$, Guiyang Liu ${ }^{1,2}$, Shaoping Feng ${ }^{1,2, *}$, Xianlan Chen ${ }^{1,2, *}$, \\ Guowei Zhang ${ }^{1,2, *}$ \\ ${ }^{1}$ College of Science, Honghe University, Mengzi, 661199, Yunnan, P.R.China \\ ${ }^{2}$ Local Characteristic Resource Utilization and New Materials Key Laboratory of Universities in \\ Yunnan, Honghe University, Mengzi, 661199, Yunnan, China \\ *E-mail: shaopingfeng@126.com, 13489086418@163.com, yunnmzh@126.com
}

doi: $10.20964 / 2021.07 .56$

Received: 10 March 2021 / Accepted: 27 April 2021 / Published: 31 May 2021

\begin{abstract}
A chemical reduction technique at low temperature was employed to synthesize $\mathrm{Au}$ and $\mathrm{Cu}$ nanoparticle chains (Au@Cu NCs) with sodium citrate as the growth reducing agent, stabilizer and structure directing agent, chloroauric acid $\left(\mathrm{HAuCl}_{4}\right)$ and copper chloride $\left(\mathrm{CuCl}_{2}\right)$ as metal precursors. Then, the $\mathrm{Au} @ \mathrm{Cu}$ NCs were dropped on glassy carbon electrode (GCE) to prepare an electrochemical sensor (Au@Cu $\mathrm{NCs} / \mathrm{GCE}$ ) for sensing piroxicam. The electrochemical behaviors on $\mathrm{Au} @ \mathrm{Cu} \mathrm{NCs} / \mathrm{GCE}$ of piroxicam were investigated in detail. The electrochemical sensor for piroxicam exhibited a linear range of 0.04$1.00 \mathrm{mM}$ at desired conditions. In particular, $\mathrm{Au} @ \mathrm{Cu} \mathrm{NCs} / \mathrm{GCE}$ was successfully applied for determination of piroxicam liniments samples with satisfactory recovery range (92.86-101.22\%) and relative standard deviation (RSD, 2.95-4.69 \%), indicating its reasonability and feasibility for piroxicam determination.
\end{abstract}

Keywords: Nanoparticle chains; Au@Cu NCs; Piroxicam; Electrochemical sensor

\section{FULL TEXT}

(C) 2021 The Authors. Published by ESG (www.electrochemsci.org). This article is an open access article distributed under the terms and conditions of the Creative Commons Attribution license (http://creativecommons.org/licenses/by/4.0/). 